6. The Extended Negative Hypergeometric Eistribution, (Preliminary Report), P. R. MrLch, Naval Postgraduate School.

7. An Iterative Solution for the Simple Stochastic Epidemic, N. C. Severo, State Uiniversity of New York at Buffalo.

\title{
PUBLICATIONS RECEIVED
}

Bartlett, M. S. (1967). An Introduction to Stochastic Processes. Cambridge University Press. xvi +362 pp. $\$ 9.50$.

Drooyan, J. and Hadel, W. (1967). Trigonometry. The Nacmillan Company. $\mathrm{x}+358$ pp. $\$ 5.50$.

Fisk, P. R. (1967). Stochastically Dependent Equations. Griffin's Statistical Nonograph No. 21. Hafner Publishing Company. vii + 181 pp. $\$ 6.40$.

Gelfand, I. M., Glagoleva, and Kirillov, A. A. (1967). The Methods of Coordinates. The M.I.T. Press. viii +69 pp. $\$ 1.50$.

Goodman, A. W. (1967). Modern Calculus with Analytic Geometry. Volume 1. The Macmillan Company. xxiii +808 pp. $\$ 10.95$.

Haight, F. A. (1967). Handbook of the Poisson Distribution. John Wiley \& Sons. $\mathrm{xi}+168$ pp. $\$ 9.50$.

Hope, K. (1967). Elementary Statistics. Pergamon Press. xii + 101 pp. $\$ 4.00$.

Hyatt, H. R. and Carico, C. C. (1967). Modern Plane Geometry for Colleae. Students. The Macmillan Company. xi +452 pp. $\$ 7.95$.

Levenson, Morris E. (1967). Maxima and Minima. The Macmillan Company. xiv +146 pp. $\$ 2.95$.

Maclane, Saunders and Birkoff, Garrett. (1967). Algebra. The Macmillan Company. xix + 598 pp. $\$ 11.95$.

Neumann, Hanna. (1967). Varieties of Groups. Springer-Verlag New York Inc. $x i+192$ pp. $\$ 11.50$.

Rahman, N. A.' (1967). Exercises in Probability and Statistics. Hafner Publishing Company. xi +307 pp. $\$ 10.50$.

Simon, Arthur B. (1967). First Year Calculus. The Macmillan Company. xiv +465 pp. $\$ 9.95$.

Smiтh, R. E. (1967). The Bases of Fortran. Control Data Institute. vii +253 pp. $\$ 3.50$.

Zaring, - (1967). An Introduction to Analysis. The Macmillan Company. $\mathrm{xi}+364$ pp. $\$ 9.95$. 